\title{
MASS DISTRIBUTION OF PARTICULATE MATTER PRODUCED DURING ABRASION OF ASPHALT MIXTURES IN LABORATORY
}

\begin{abstract}
Non-exhaust emissions of particulate matter from road traffic can come from abrasion of vehicle parts (tyres, brake linings, clutch and bodywork) or from pavement surface abrasion and also from resuspension of dust. A differentiation between PM emissions from road pavement abrasion and resuspension is very difficult due to their similar elemental composition. The research is focused on abrasion of pavement surface from asphalt mixtures. Experimental tests are conducted for measuring of particulate matter production in the atmosphere during the rutting of various asphalt mixtures used for wearing courses. The tests are performed in wheel tracking machine in the laboratory. Particle sampling in the laboratory makes it possible to sample PM with very low contamination from surrounding sources and no influence from exhaust emissions. The paper presents an example of the results of measurements on six trial samples of asphalt mixtures with different composition.

Keywords: Particulate matter (PM), abrasion, wearing courses, laboratory tests, chemical elements.
\end{abstract}

\section{Introduction}

The air is polluted mainly by traffic, industry, agriculture and households. Although the production of emissions has been decreased in recent decades and some of the contaminants have been reduced, the problem is far from solving. These are particularly the two substances - particulate matter (PM) and ground-level ozone, which cause respiratory problems, cardiovascular diseases and reduce life expectancy [1].

Road traffic is one of the main sources of pollution in the vicinity of roads. Particulate matter air pollution can come from combustion or non-combustion processes. Non-combustion emissions of particulate matter can come from abrasion of vehicle tyres, abrasion of brake linings, clutch, and vehicle bodywork, abrasion of pavement surface and also from resuspension of dust (Fig. 1) [2, 3 and 4].

We have decided to deal with non-combustion emissions, especially with the production of particulate matter from abrasion of the pavement surface. This decision is based on information obtained from several foreign and Slovak scientific papers [5 and 6], studies and researches about production of particulate matter from road traffic [7, 8, 9 and 10]. The issue of abraded particulate matter (PM) from pavement surfaces and the contribution of those emissions to air pollution is mostly solved in the Nordic countries [11and 12]. This problem has attracted attention especially in Norway, Finland and Sweden because of the use of studded tyres and winter gritting.

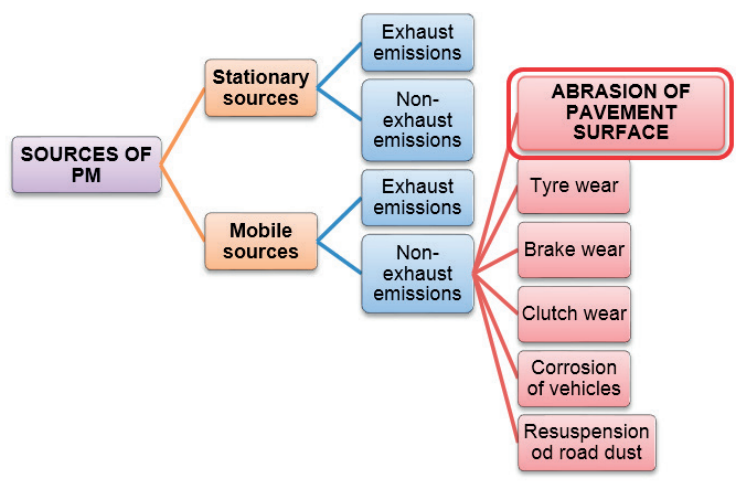

Fig. 1 The separation of particulate matter sources and non-exhaust emissions of mobile sources

It is a very difficult process to identify pavement surface abrasion as a source of particulate matter and separate it from other abrasions and quantify its share of the amount of produced particulate matter directly in the field. One possible way leads through chemical analysis of particulate matter and multivariate statistical analysis. But it is necessary to know which chemical elements this source (pavement surface) can contain and release.

\footnotetext{
* 'Dasa Fullova, ${ }^{1}$ Daniela Durcanska, 'Dusan Jandacka, ${ }^{2}$ Adriana Estokova

${ }^{1}$ Department of Highway Engineering, Faculty of Civil Engineering, University of Zilina, Slovakia

${ }^{2}$ Technical Institute of Environmental Engineering, Faculty of Civil Engineering, University of Kosice, Slovakia

E-mail: dasa.fullova@fstav.uniza.sk
} 
There are few data about the chemical composition of road surface materials and particulate matter from abrasion of wearing courses available in the literature. Emissions from abrasion of pavement surface are more difficult to quantify separately than emissions from tyre and brake wear.

The task of our research is to monitor the separation of abraded particulate matter from the selected group of samples used for the asphalt wearing courses. An important phase of the research is to determine chemical elements in the collected particulate matter and to confront it with the representation of these elements in the chemical composition of the asphalt mixture. The next step is to attempt to determine the share of the mechanical separation of PM from the pavement by evaluating the chemical composition of the materials used in the studied asphalt mixtures of wearing courses and subsequently collected particulate matter. The research is aimed at finding dependence between the composition of asphalt mixture and collected PM.

An aggregate, asphalt binder, additives, or recycled material are basic materials for the production of different types of asphalt mixtures. The choice of materials and technological procedures for their construction or renovation affects the structural design of pavements. Vehicle motions cause mechanical wearing of the asphalt pavement surface - wearing course by vehicle tyres. That leads to gradual fragmentation and abrasion of aggregate.

\section{Methodology of experimental measurements}

The resulting abrasion and production of inhalable PM emissions are dependent on a number of factors that are difficult to quantify in real world environments. Therefore, the measurements are performed in the laboratory at the Department of Highway Engineering. Particle sampling in the laboratory makes it possible to sample pure abraded particles with very low contamination from ambient particles. The samples of asphalt mixtures for creation of wearing courses are used for laboratory measurements. The samples are rutted in wheel tracking machine DYNA-TRACK which is used to assess the rutting resistance of asphalt materials under conditions, which simulate the effect of traffic (Fig. 2). The objective of the experimental measurements is to verify the effect of the composition of the asphalt mixture for the production of PM emissions.

Each of the tested samples is specific in its composition - the type of asphalt, the amount of asphalt, the type of aggregate, the different lines of granularity of aggregate. In connection with the material are created samples with different structure of surface, which can ultimately affect abrasion of the samples. Detailed specification of asphalt mixtures is described in the catalog [13].

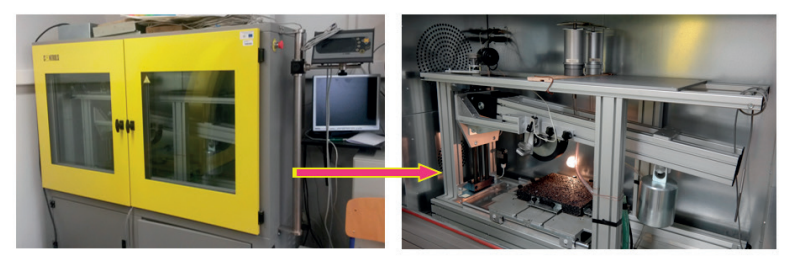

Fig. 2 Wheel tracking machine DYNA-TRACK

The wheel tracking equipment consists of a loaded wheel, which bears on a sample held on a moving table. The wheel tracker is fitted with a temperature controlled cabinet with a temperature range from laboratory environment to $65^{\circ} \mathrm{C} \pm 1.0^{\circ} \mathrm{C}$. The wheel is fitted with a solid rubber tyre of outside diameter $200 \mathrm{~mm}$. The wheel load under standard conditions is $700 \pm 10 \mathrm{~N}$. The sample may be either a $200 \mathrm{~mm}$ diameter core or a $300 \mathrm{x} 400 \mathrm{~mm}$ slab of asphalt mixture from $25 \mathrm{~mm}$ to $100 \mathrm{~mm}$ thick [14].

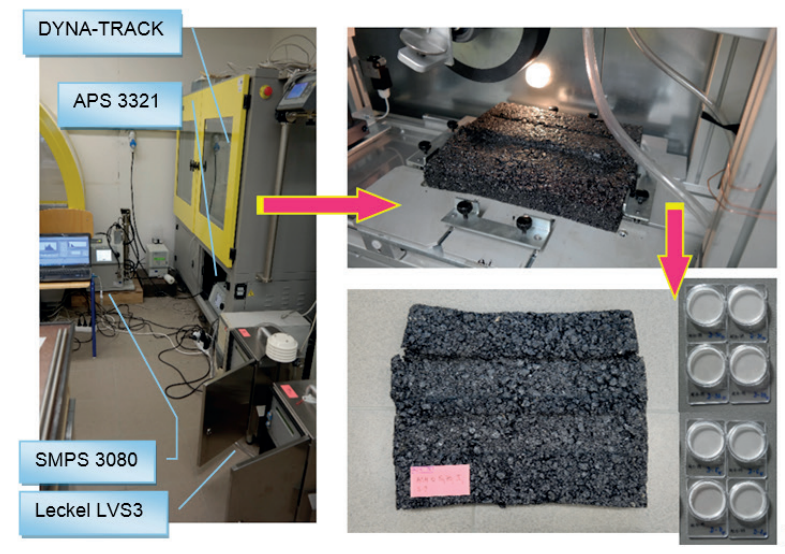

Fig. 3 The used machine technology and rutted sample of the tested asphalt mixture (AC 11 O 50/70, II, S-9) with the contaminated nitrocellulose filters of diameter $47 \mathrm{~mm}$

The used asphalt mixture samples are plates of size 320 x $260 \mathrm{~mm}$ and thicknesses of $40 \mathrm{~mm}$. The sampling of the air from inside of the machine DYNA-TRACK during the rutting of samples is performed by equipment APS 3321 (Aerodynamic Particle Sizer) and SMPS 3080 (Scanning Mobility Particle Sizer) which intercept and distribute particle range from 0.012 to $20 \mu \mathrm{m}$ and 2 pieces of Leckel LVS3 which intercept particulate matter $\mathrm{PM}_{2.5}$ and $\mathrm{PM}_{1}$ on the filters for the subsequent chemical analysis (Fig. 3).

The air in the vicinity of the sample is circulated (it is swirled by two fans which are part of the device), so that the temperature is stable in the whole space around the sample. This is obtained by the swirling of particles produced during abrasion of the sample and their subsequent sampling by spectrometers APS, SMPS and low volume sampler Leckel. The asphalt mixture samples are rutted by typified wheel for 12 hours through the steady working 
conditions. It performs 20000 cycles during the 12 hours (i.e. 40000 running gear).

There are specified chemical elements (markers) which are contained in the basic materials of asphalt mixture for identification of particulate matter originating from the asphalt mixture abrasion. These elements will be determined by analyses of the components of the road wearing courses (asphalt mixtures), and they are the aggregate as a filler and the asphalt as a binder. Identified elements will subsequently be confronted with the elements of the particulate matter collected on the filters.

\section{The results of current chemical analyses and experimental measurements}

The tests of chemical composition of materials (aggregates, asphalt) of samples were carried out before the rutting of these asphalt mixture samples by XRF analyzer (X-ray fluorescence spectroscopy). From the analysis of each material the percentage of each selected element has been found. For the experiments the machine SPEKTRO iQ II (AMATEK, Germany) was used. It is used for analysis of the majority, minor and trace elements in all types of material with sensitivity at the level of ppm.

The tests of chemical composition were performed in the laboratory of the Faculty of Civil Engineering of the Technical University in Košice. The first step was to start with a selected group of elements ( $\mathrm{Na}, \mathrm{Mg}, \mathrm{Al}, \mathrm{V}, \mathrm{Fe}, \mathrm{Mn}, \mathrm{Ni}, \mathrm{Cu}, \mathrm{Zn}, \mathrm{As}, \mathrm{Mo}$, $\mathrm{Sb}, \mathrm{Cd}, \mathrm{Ba}, \mathrm{Pb}, \mathrm{Ca}$, and $\mathrm{Cr}$ ).

The chemical analyses were performed for all kinds of aggregates used in tested samples. In the samples aggregates from six quarries were used:

$$
\begin{array}{ll}
\Rightarrow \text { Maluzina - melaphyre1 } & \Rightarrow \text { Biely Potok - dolomite } \\
\Rightarrow \text { Badin - andesite } & \Rightarrow \text { Tunezice - silicious limestone } \\
\Rightarrow \text { Solosnica - melaphyre2 } & \Rightarrow \text { Zirany - quartzite }
\end{array}
$$

XRF analyzer used and evaluated the powder samples (crushed aggregates). The results are shown in the following

Percentage share of the chemical elements of aggregate used in the tested samples

Table 1

\begin{tabular}{lccccccccccc}
\hline $\begin{array}{l}\text { Chemical element/ } \\
\text { Aggregate }\end{array}$ & $\mathrm{Mg}$ & $\mathrm{Al}$ & $\mathrm{Si}$ & $\mathrm{P}$ & $\mathrm{S}$ & $\mathrm{Cl}$ & $\mathrm{K}$ & $\mathrm{Ca}$ & $\mathrm{Ti}$ & $\mathrm{V}$ & $\mathrm{Cr}$ \\
\hline Melaphyre1 & 3.62 & 7.60 & 23.81 & 0.086 & 0.015 & 0.027 & 1.034 & 7.23 & 0.848 & 0.030 & 0.005 \\
\hline Andesite & 1.88 & 10.3 & 28.12 & 0.077 & 0.009 & 0.028 & 1.020 & 6.35 & 0.476 & 0.023 & $<$ \\
\hline Melaphyre2 & 6.25 & 7.87 & 23.65 & 0.151 & 0.013 & 0.035 & 0.923 & 7.13 & 0.890 & 0.032 & 0.012 \\
\hline Dolomite & 17.56 & 0.95 & 2.041 & 0.023 & 0.010 & 0.052 & $<$ & 30.42 & 0.047 & 0.011 & 0.039 \\
\hline Silicious limestone & 4.69 & 0.55 & 2.622 & 0.025 & 0.018 & 0.038 & 0.112 & 48.29 & 0.029 & 0.012 & 0.036 \\
\hline Quartzite & 1.51 & 0.24 & 0.510 & 0.004 & 0.007 & 0.022 & $<$ & 51.31 & 0.011 & 0.008 & 0.021 \\
\hline
\end{tabular}

\begin{tabular}{|c|c|c|c|c|c|c|c|c|c|c|}
\hline $\begin{array}{l}\text { Chemical element/ } \\
\text { Aggregate }\end{array}$ & $\mathrm{Mn}$ & $\mathrm{Fe}$ & $\mathrm{Cu}$ & $\mathrm{Zn}$ & $\mathrm{Rb}$ & $\mathrm{Sr}$ & $\mathrm{Y}$ & $\mathrm{Ba}$ & $\mathrm{Ta}$ & $\begin{array}{l}\text { Share of } \\
\text { identified } \\
\text { elements }\end{array}$ \\
\hline Melaphyre1 & 0.197 & 5.747 & 0.005 & 0.011 & 0.005 & 0.014 & 0.002 & 0.019 & 0.037 & $50.35 \%$ \\
\hline Andesite & 0.098 & 4.068 & 0.003 & 0.004 & 0.004 & 0.030 & 0.001 & 0.013 & 0.029 & $52.56 \%$ \\
\hline Melaphyre2 & 0.205 & 7.466 & 0.004 & 0.023 & 0.004 & 0.019 & 0.004 & 0.015 & 0.044 & $54.76 \%$ \\
\hline Dolomite & 0.040 & 0.352 & $<$ & $<$ & 0.001 & 0.010 & $<$ & $<$ & $<$ & $51.58 \%$ \\
\hline Silicious limestone & 0.035 & 0.348 & $<$ & $<$ & 0.001 & 0.070 & $<$ & $<$ & $<$ & $56.89 \%$ \\
\hline Quartzite & $<$ & 0.14 & $<$ & $<$ & $<$ & 0.015 & $<$ & $<$ & $<$ & $53.82 \%$ \\
\hline
\end{tabular}

Percentage share of the elements of aggregate used in the tested samples - continuation

Note: < - Elements under the detection limit 
Tables 1 and 2. The maximum obtained values are highlighted in blue.

The chemical composition analysis (XRF-analyzer) showed that the tested asphalt (binder of asphalt mixture) does not contain any elements from the selected group of elements. Therefore, it will be necessary to extend or replace some elements by organic elements, or by organic compounds. Asphalt contains about $4.8 \%$ of inorganic elements and the rest are organic elements. The sulfur $\mathrm{S}$ has the largest representation, it represents 4.19\%. Silicon $\mathrm{Si}(0.21 \%)$ and chlorine $\mathrm{Cl}(0.17 \%)$ represent a higher share of identified inorganic elements.

Till now, the measurements of particulate matter were performed on six trial samples of asphalt mixtures with different composition. Two plates of each mixture were rutted in the laboratory and each plate was rutted two times:

$$
\begin{aligned}
& \Rightarrow \mathrm{AC} 11 \mathrm{O} 50 / 70, \mathrm{II}, \mathbf{D}-\mathbf{5} \quad \Rightarrow \mathrm{AC} 11 \text { O 50/70, II, K - } 4 \\
& \Rightarrow \mathrm{AC} 11050 / 70, \text { II, R - } 9 \quad \Rightarrow \text { AC } 110 \text { 50/70, II, S - } 9 \\
& \Rightarrow \text { AC } 11 \text { O PMB 45/80-75, } \Rightarrow \text { SMA } 11 \text { PMB 45/80-75, } \\
& \text { I, R - } 8
\end{aligned}
$$

All six samples had the same conditions in the space of rutting during abrasion of asphalt mixtures. The measurements were performed in the period from $24^{\text {th }}$ August 2015 till $23^{\text {rd }}$

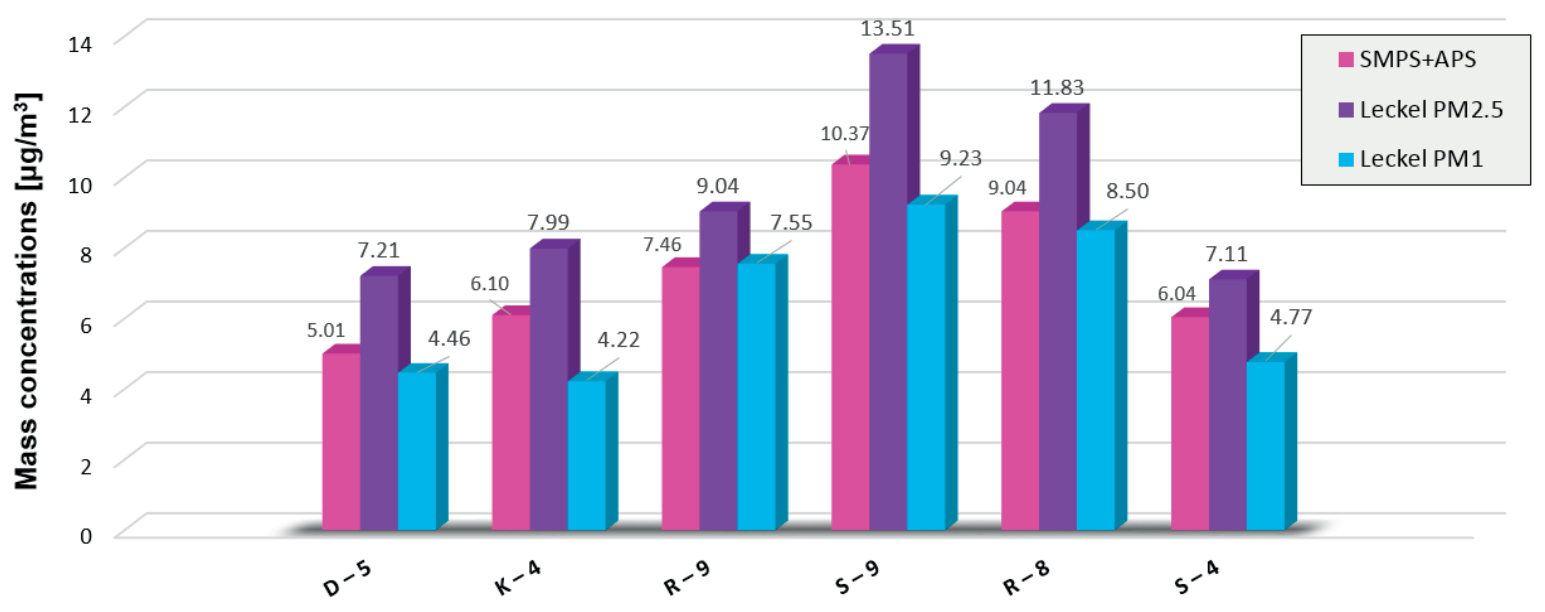

Mark of asphalt mixture sample

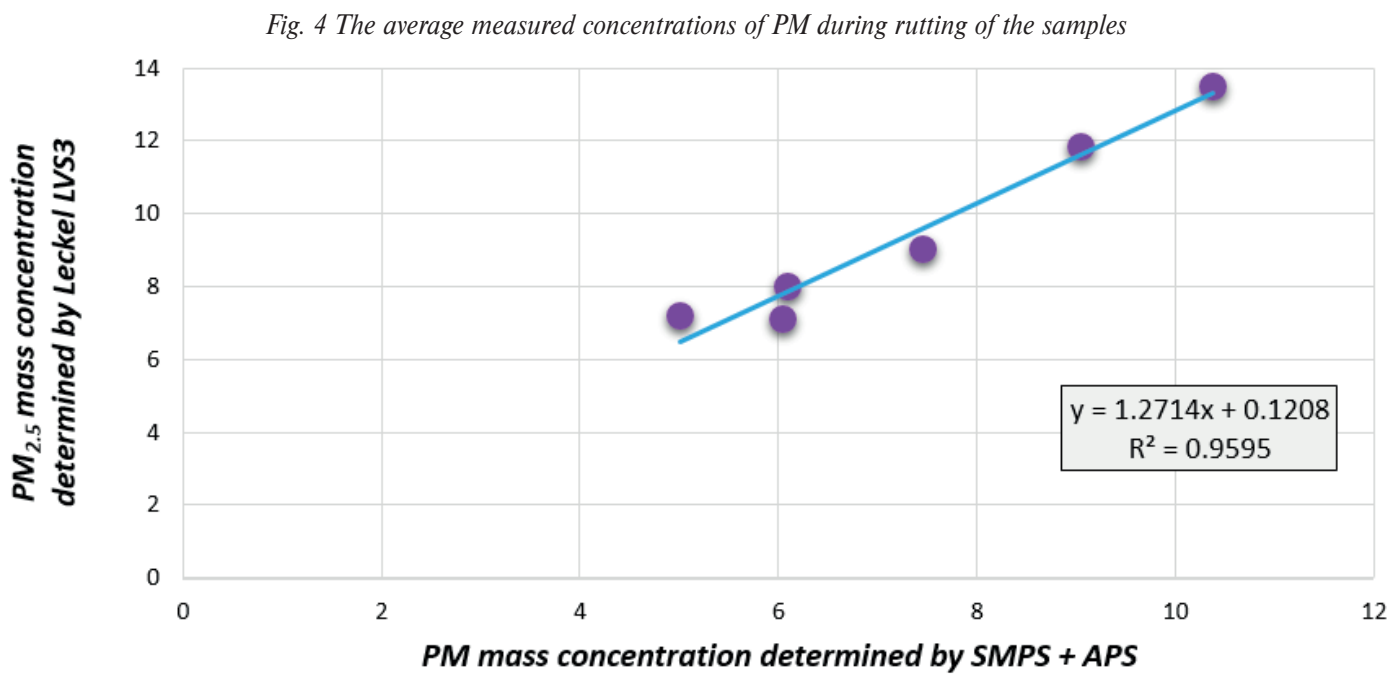

Fig. 5 The correlation between particulate matter mass concentrations determined by spectrometers (SMPS+APS) and low volume sampler (Leckel LVS3) 

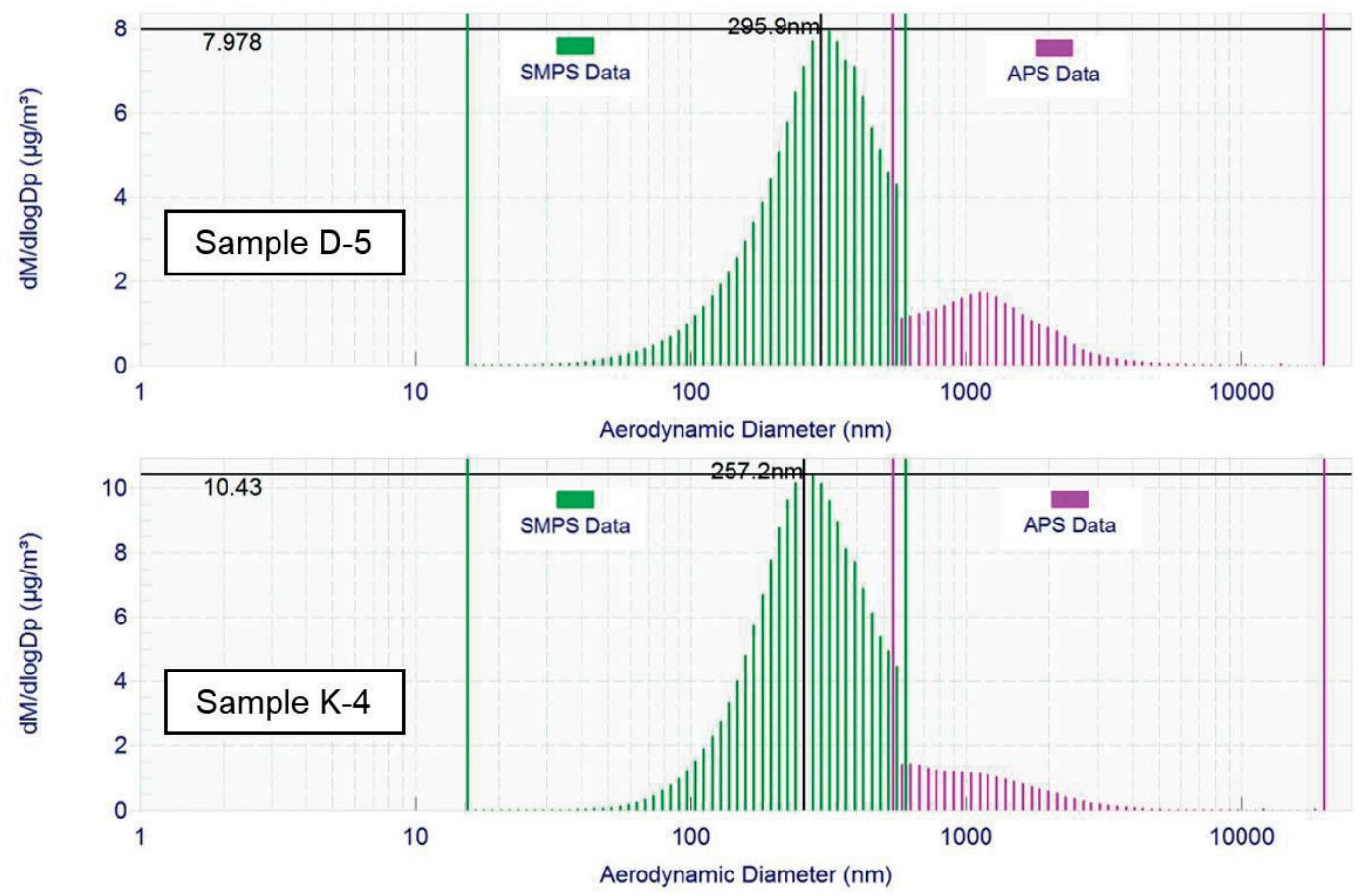

Fig. 6 The average mass distribution of particulate matter according to the aerodynamic diameter for the rutted samples $\boldsymbol{D}-\mathbf{5}$ and $\boldsymbol{K}-4$
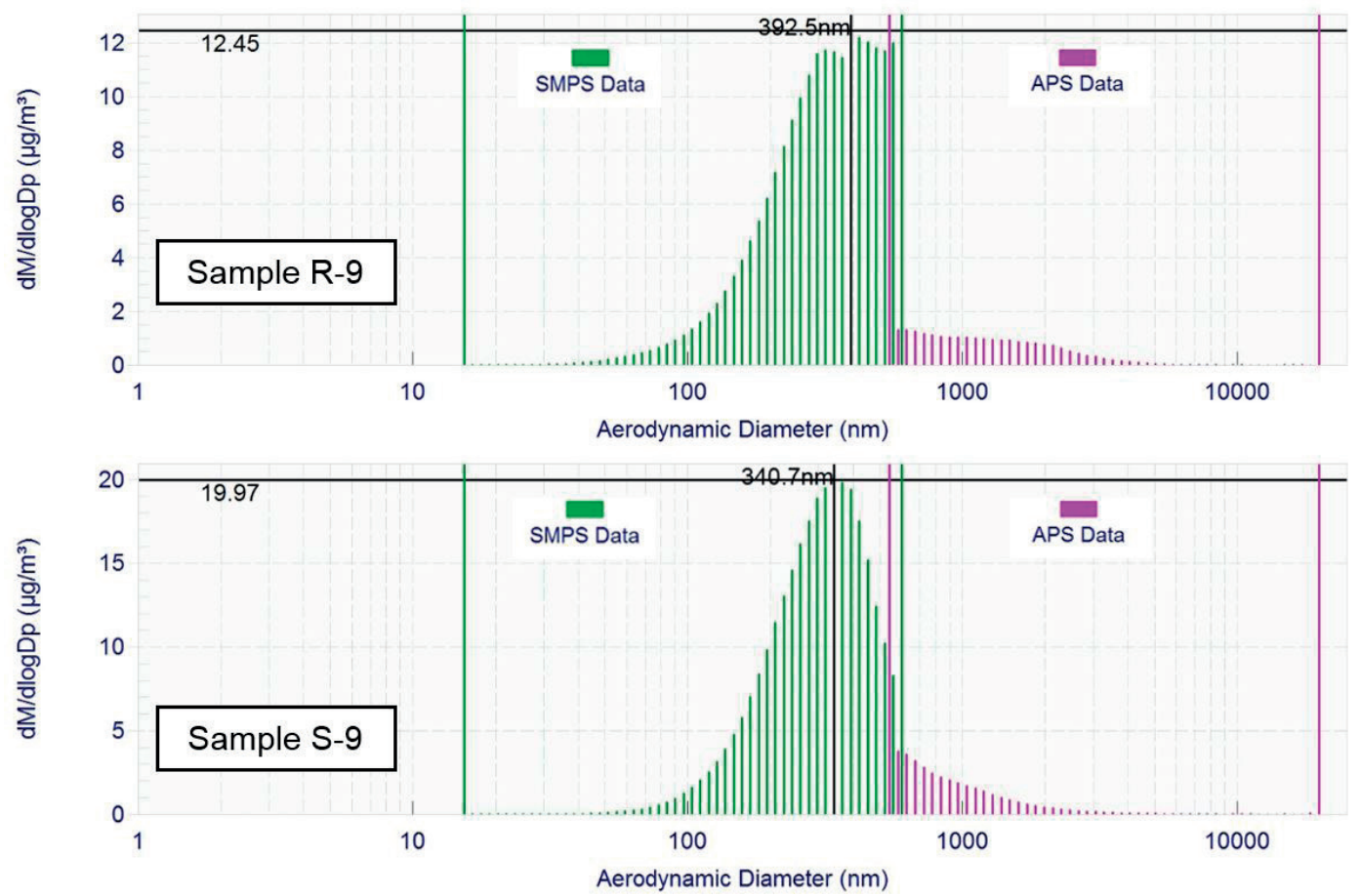

Fig. 7 The average mass distribution of particulate matter according to the aerodynamic diameter for the rutted samples $R-9$ and $S-9$ 

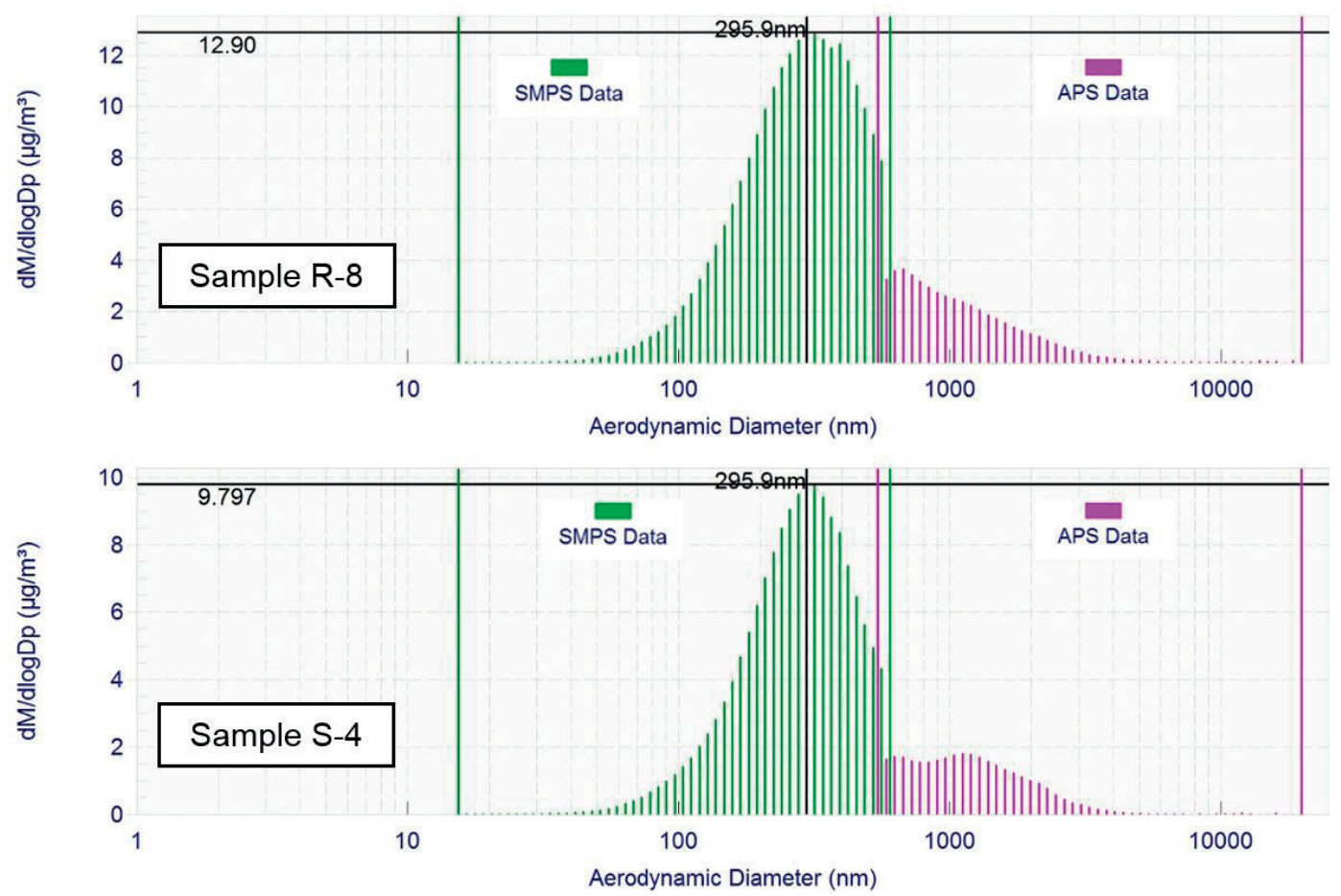

Fig. 8 The average mass distribution of particulate matter according to the aerodynamic diameter for the rutted samples $\boldsymbol{R}-\boldsymbol{8}$ and $\boldsymbol{S}-\mathbf{4}$

September 2015. The total length of measurement was 12 hours. The four measurements were performed for each of the asphalt mixtures, it means two ruttings on each sample. The air sampling from inside of the machine DYNA-TRACK during the rutting was performed by means of spectrometers SMPS, APS and two Leckels. In order to determine mass concentrations by SMPS and APS, 180 air samplings were performed. The air sampling was carried out every 4 minutes during 12 hour measurements. Mass concentrations of $\mathrm{PM}_{1}$ and $\mathrm{PM}_{2.5}$ were determined by the gravimetric method (Leckels) and 12 hour air samplings were performed. The results of the measured PM are shown in the following figure as mass concentrations (Fig. 4).

Spectrometers APS 3321 and SMPS 3080 intercepted and distributed particle range from 0.012 to $20 \mu \mathrm{m}$ and 2 pieces of Leckel LVS3 intercepted particulate matter $\mathrm{PM}_{25}$ and $\mathrm{PM}_{1}$. Particulate matter of concern includes "fine particles" $\mathrm{PM}_{2.5}$ with a diameter smaller than $2.5 \mu \mathrm{m}$ and "ultrafine particles" $\mathrm{PM}_{1}$ smaller than $1 \mu \mathrm{m}$ in diameter.

The highest concentrations of particulate matter were measured for the mixture $\mathrm{AC} 11$ with classic binder, especially for the sample wih the mark S - 9 (used aggregates - melaphyre and quartzite) and the lowest concentrations of particulate matter for the sample with the mark D - 5 (used aggregate - siliceous limestone).

Particulate matter concentrations were determined by two methods. The first is determination by the two spectrometers
SMPS and APS and the second is determination by low volume sampler Leckel. The results correlate with each other - Leckel $\mathrm{PM}_{2.5}$ vs. SMPS+APS ( $\left.\mathrm{r}=0.98\right)$ (Fig. 5).

The following Figs. 6 - 8 present the average mass distribution of PM according to the aerodynamic diameter for six rutted mixtures. The values are given in the units $\mathrm{dM} / \mathrm{d} \log \mathrm{Dp}\left(\mu \mathrm{g} / \mathrm{m}^{3}\right)$ for the mass concentration at 32 aerodynamic diameter for a decade.

The values measured by spectrometers APS 3321 are highlighted in violet and the values measured by SMPS 3080 are highlighted in green. The mode (the aerodynamic diameter that appears most often in a set of data) at the mass concentration is $296 \mathrm{~nm}$ for the rutted sample with the mark D - 5, $257 \mathrm{~nm}$ for the sample $\mathrm{K}-4,393 \mathrm{~nm}$ for the sample with the mark $\mathrm{R}-9$ and $341 \mathrm{~nm}$ for the sample $\mathrm{S}-9$ (Figs. 6 - 7). The mode is $296 \mathrm{~nm}$ for the rutted sample with the mark R -8 and also $296 \mathrm{~nm}$ for the sample with the mark $\mathrm{S}-4$ (Fig. 8).

As regards the comparison of six different asphalt mixtures, the sample with the mark $\mathrm{S}$ - 9 shows the highest mass concentration of particulate matter and the sample with the mark D - 5 shows the lowest concentration. The average mass concentration of the sample D - 5 is by $5.36 \mu \mathrm{g} / \mathrm{m}^{3}$ less than the average mass concentration of the sample $S-9$. These concentrations were determined by means of spectrometers APS and SMPS. The difference between these two samples was determined on $6.30 \mu \mathrm{g} / \mathrm{m}^{3}$ for the particulate matter of fraction 
$\mathrm{PM}_{2.5}$ and $4.77 \mu \mathrm{g} / \mathrm{m}^{3}$ for the particulate matter of fraction $\mathrm{PM}_{1}$ by using the gravimetric method (by the machine Leckel).

\section{Discussion to the issue}

For our research the initial measurements of abrasion of asphalt mixture samples for wearing courses and chemical analysis of aggregates and asphalt were carried out. Chemical analyses revealed a number of facts about content of individual elements in the investigated materials. While the elements such as $\mathrm{Si}$ and $\mathrm{Ca}$ have a dominant representation in the aggregates, the presence of $\mathrm{Mg}, \mathrm{Al}$ and $\mathrm{Fe}$ is lower. Asphalt contains primarily elements of organic chemistry but sulfur S prevails over other inorganic elements.

The findings from chemical analyses can be further applied for the research of particulate matter released from asphalt roads abrasion. The subsequent phase of the research will be to determine chemical elements in the collected particulate matter and to confront it with the representation of these elements in the chemical composition of the asphalt mixture. Till now 24 tests have been performed and 6 asphalt mixtures have been rutted in wheel tracking machine. Four measurements of PM concentrations are available for each type of asphalt mixture.

The samples were different not only by the used aggregate type but also by the used binder. The highest concentration of particles PM was measured for the sample S - 9 (AC 11) with the asphalt 50/70. The lower values of mass concentration were measured for the sample S - 4 (SMA 11) with modified asphalt PMB 45/80-75 and the lowest mass concentration was determined for the sample with the mark D - 5 (AC 11) with the asphalt 50/70. Aerodynamic diameter is the substantial value of measured particulate matter during the rutting of asphalt mixture samples by means of APS and SMPS. The aerodynamic diameter is less than $1 \mu \mathrm{m}$.

The continuation of our research should include a comparison of individual types of asphalt mixtures by monitoring the chemical composition of produced particulate matter and subsequent comparison of mixtures from the perspective of particulate matter production from the pavement surface. As this paper presents partial results, the task for the continuation of the research is to test and compare the largest possible number of asphalt mixtures. The final evaluation should be based on the results of a sufficient number of measurements for statistical evaluation of the experiment.

\section{References}

[1] EEA Report No 5/2014. Air quality in Europe - 2014 report

[2] AMATO, F., et al.: Urban Air Quality: The Challenge of Traffic Non-Exhaust Emissions. J. of Hazardous Materials, 275, 31-36, 2014. Retrieved from www.scopus.com

[3] JANDACKA, D.: Road Transport Impact on the Occurrence of Particulates, Dissertation thesis. University of Zilina, 134 p., 2012.

[4] JANDACKA, D.: Contributory Assessment of Creation of $\mathrm{PM}_{10}$ as Impacted by Vehicular Traffic Based on the Presence of Heavy Metals. Communications - Scientific Letters of the University of Zilina. vol. 15, No. 3, 2013, pp. 96-101, ISSN 1335-4205.

[5] DURCANSKA, D.: Analysis of Particulate Matter Composition. Communications - Scientific Letters of the University of Zilina, vol. 12, No. 3A, 2010, 17-22, ISSN 1335-4205.

[6] POSPISIL, J., LICBINSKY, R., HUZLIK, J.: Dispersion of Pollutants from Line Sources in Small Municipalities. Transactions on Transport Sciences, vol. 7, No. 4, 2014, 161-168. ISSN 1802-971X.

[7] DURCANSKA, D., et al.: Analysis of Methods of Evaluation of the Air Pollution from Road Traffic: Analysis Task. Zilina: Faculty of Civil Engineering, Department of Highway Engineering, September 2014.

[8] GEHRIG, R., ZEYER, K., BUKOWIECKI, N., LIENEMANN, P., POULIKAKOS, L. D., FURGER, M., BUCHMANN, B.: Mobile Load Simulators - A Tool to Distinguish between the Emissions Due to Abrasion and Resuspension of PM 10 from Road Surfaces. Atmospheric Environment, 44(38), 4937-4943, 2010.

[9] PIRJOLA, L., KUPIAINEN, K. J., PERHONIEMI, P., TERVAHATTU, H., VESALA, H.: Non-Exhaust Emission Measurement System of the Mobile Laboratory SNIFFER. Atmospheric Environment, 43(31), 4703-4713, 2009.

[10] TERVAHATTU, H., KUPIAINEN, K. J., RAISANEN, M., MAKELA, T., HILlAMO, R.: Generation of Urban Road Dust from Anti-Skid and Asphalt Concrete Aggregates. J. of Hazardous Materials, 132(1 spec. iss.), 39-46, 2006.

[11] FOLKESON, et al., SPENS: Sustainable Pavements for European New Member States, Guidelines for the environmental assessment of various pavement types including recommendations to road authorities in NMS, European commission DG research, Sixth framework programme, 29 May 2009.

[12] GUSTAFSSON, M., BLOMQVIST, G., GUDMUNDSSON, A., DAHL, A., JONSSON, P., SWIETLICKI, E.: Factors Influencing $\mathrm{PM}_{10}$ Emissions from Road Pavement Wear. Atmospheric Environment, 43(31), 4699-4702, 2009.

[13] KLAZ 1/2010 Catalog Sheets - Asphalt Mixture Guide. MDPaT SR, 2010.

[14] Wheel Tracking Machine DYNA-TRACK. Cernusco, Italy: Controls S.R.L., 2000. 